\title{
Is There an Earthquake Weather?
}

\author{
Michel Parrot1,2, Jean-Louis Pinçon ${ }^{1,2}$ \\ ${ }^{1}$ LPC2E, CNRS, Orléans, France \\ ${ }^{2}$ University of Orléans, Orléans, France \\ Email:mparrot@cnrs-orleans.fr
}

How to cite this paper: Parrot, M. and Pinçon, J.-L. (2020) Is There an Earthquake Weather? Open Journal of Earthquake Research, 9, 69-82.

https://doi.org/10.4236/ojer.2020.92005

Received: November 14, 2019

Accepted: March 9, 2020

Published: March 12, 2020

Copyright (C) 2020 by author(s) and Scientific Research Publishing Inc. This work is licensed under the Creative Commons Attribution International License (CC BY 4.0).

http://creativecommons.org/licenses/by/4.0/

\section{(c) (i) Open Access}

\begin{abstract}
The aim of this study is to check if there is a relationship between the seismic activity and the whistlers observed by the micro-satellite DEMETER. Whistlers are the waves emitted by lightning strokes during thunderstorm activity. They use to propagate in the Earth-ionosphere waveguide but also in the ionosphere and the magnetosphere mainly along the magnetic field lines. Due to this reason we have checked the whistler occurrence not close to earthquake epicenters but close to the magnetically conjugate point of these epicenters at the satellite altitude. The number of whistlers is given by a neural network in operation onboard the satellite. It appears that the whistler amplitude is attenuated at the satellite altitude around the magnetic equator. It is why we have removed the earthquakes occurring at low geomagnetic latitudes in the statistic. The whistler rate is normalized with a background value to take into account the seasons and the epicenter locations. A superposed epoch method is used to display the results between -15 and +5 days around the earthquake day and up to $1000 \mathrm{~km}$ from the conjugate point of the epicenters. It is shown that the whistler rate is higher the day before the earthquake at a distance less than $200 \mathrm{~km}$. It would be unrealistic to believe in the possibility to use this study for earthquake prediction because everyday thunderstorm activity reliably masks seismic effects. But it is further evidence that there is a lithosphere-atmosphere-ionosphere coupling at the time of the seismic activity.
\end{abstract}

\section{Keywords}

Data Processing, Earthquake, Whistler, Ionosphere

\section{Introduction}

The possible relation between thunderstorm activity and seismic activity is an old question. A long time ago some rough correlation between earthquakes and lightning strokes has been shown during summer time in the Kwantô district in 
Japan [1]. Afterwards only case studies have been mainly done. Unusual variations of the intensity of the sferics received at $6 \mathrm{kHz}$ and $9 \mathrm{kHz}$ at Agartala, India (latitude, $23^{\circ} \mathrm{N}$; longitude, $91.4^{\circ} \mathrm{E}$ ) have been reported by [2] some days before an earthquake occurring on October 8, 2005 at Muzaffarabad, Pakistan (latitude, $34.53^{\circ} \mathrm{N}$; longitude, $73.58^{\circ} \mathrm{E}$ ). The number of sferics was highest on the day of the earthquake. A sferic (or atmospheric) is the wave emitted by a lightning stroke which propagates in the Earth-ionosphere waveguide. Prior to an M8.2 earthquake occurring on 24 May 2013 near the Kamchatka peninsula, increase of the sferic amplitudes has been observed [3]. It was noticed in [4] that anomalous electromagnetic signals at frequencies of $3-60 \mathrm{kHz}$ prior to earthquakes can be due to local thunderstorms. A change of spectral density in high frequency bands has been found in [5] from several days to several hours before an earthquake. Some powerful thunderstorm activities have been observed prior to major earthquakes [6]. Anomalous thunderstorm activities above epicenters have been observed approximately 5 days before an earthquake event [7]. Concerning the M7.2 Hyogoken-Nanbu earthquake of January 17, 1995 in Japan, strong lightning discharges have been detected in association with intense radio noises one week prior to the main shock [8] [9]. It has been noticed an increase in the amplitude of lightning electromagnetic signals (atmospherics) received at Yakutsk, 12 - 14 days before the M9 Tohoku earthquake in Japan [10]. Recently, abnormal thunderstorm activity has been observed over the epicenter area one month before the M8.3 Illapel earthquake in Chile [11]. But several authors using low resolution data were not able to check the nature of the electromagnetic emissions observed prior to earthquakes and even some authors try to remove waves due to lightning strokes considering that they could not be related to earthquakes [12].

A more global analysis has been done in [13] [14] close to Taiwan. They have performed a statistical correlation between lightning activities and $M \geq 5.0$ earthquakes occurring during 1993-2004. Their analyses indicate that the emissions enhance 5 - 7 days before the earthquakes above the epicenters and are proportional to the earthquake magnitude.

The purpose of this paper is to examine if there is likely a connection between the occurrence of earthquakes and the ionospheric signature of thunderstorm activity in the epicenter area using the data of the DEMETER satellite. The DEMETER data and the earthquake selection are presented in Section 2. The method used to process these data is described in Section 3 where results are also shown. They are discussed in Section 4 whereas conclusions are given in Section 5. Note that our study is not related to earthquake lights (see for example [15] [16] [17]) because these lights are faint and diffuse and correspond to a very different phenomenon.

\section{The Data}

\subsection{The Whistlers}

Thunderstorm activity is very common in the Earth's atmosphere and each 
lightning stroke triggers an electromagnetic wave in a huge frequency range which propagates in the Earth-ionosphere waveguide. Depending on the frequency range and the ionospheric conditions, a part of the wave energy can cross the ionosphere and propagates in the magnetosphere along magnetic field lines with a frequency dispersion. It is called a whistler. Onboard the low altitude satellite DEMETER, RNF is a dedicated experiment based on a neural network to count these whistlers and to classify them by dispersion with a time resolution of 0.1024 s. Details about the RNF experiment can be found in [18] [19], and [20]. Here we will consider the whistlers with low frequency dispersion, i.e., the whistlers which corresponds to waves emitted just below the satellite. After a learning phase, RNF was operational from May 2005 until December 2010 the end of the mission. The lightning activity is naturally function of many parameters as the location and the seasons. But a recent study has shown that a map of whistler activity is very different from a map of lightning activity [20]. The main point is that the whistlers with low dispersion are strongly attenuated close to the magnetic equator.

DEMETER is nearly sun synchronous and measurements are only done at two different local times: 10.30 and 22.30 LT. Only night time whistlers recorded by DEMETER have been considered here because they are more numerous than during day time. This is due to the thunderstorm activity which is lower in the morning, and to the whistler intensity absorption since the ionospheric density is higher.

\subsection{The Earthquakes}

Earthquakes with magnitude $M \geq 4.8$ have been selected in the USGS database (http://www.usgs.gov). It represents a database of 18,752 events with time, location, magnitude $\mathrm{M}$ and depth $\mathrm{d}$. Considering that the observation of whistlers on board DEMETER dramatically decreases close to the magnetic equator and that the aim of our study is to investigate a possible relation with the earthquake locations, all earthquakes close to the magnetic equator i.e. with $\mid$ mag. lat. $\mid \leq 20^{\circ}$ have been removed (see Figure 1). It remains $N=6847$ events. As we have seen in the previous section that the whistlers propagate along the magnetic field lines we do not consider the position of the epicenters at the Earth's surface but the magnetically conjugate points of these epicenters at the altitude of the satellite $(660 \mathrm{~km})$ in the same hemisphere. It means that, either in the Northern hemisphere or in the Southern hemisphere, the epicenter positions are slightly shifted towards the equator to take into account the whistler propagation (see Figure 2). For example, concerning an earthquake with an epicenter located at $\left(39.22^{\circ} \mathrm{N}\right.$, $\left.41.08^{\circ} \mathrm{E}\right)$ the study of the whistler rate will be done at the location $\left(35.28^{\circ} \mathrm{N}\right.$, $\left.40.73^{\circ} \mathrm{E}\right)$. In the following this location will be called Epicenter Conjugate point (ECP).

Another key problem related to the statistics with earthquakes is the occurrence of aftershocks. When we are looking for possible effects a few hours or 


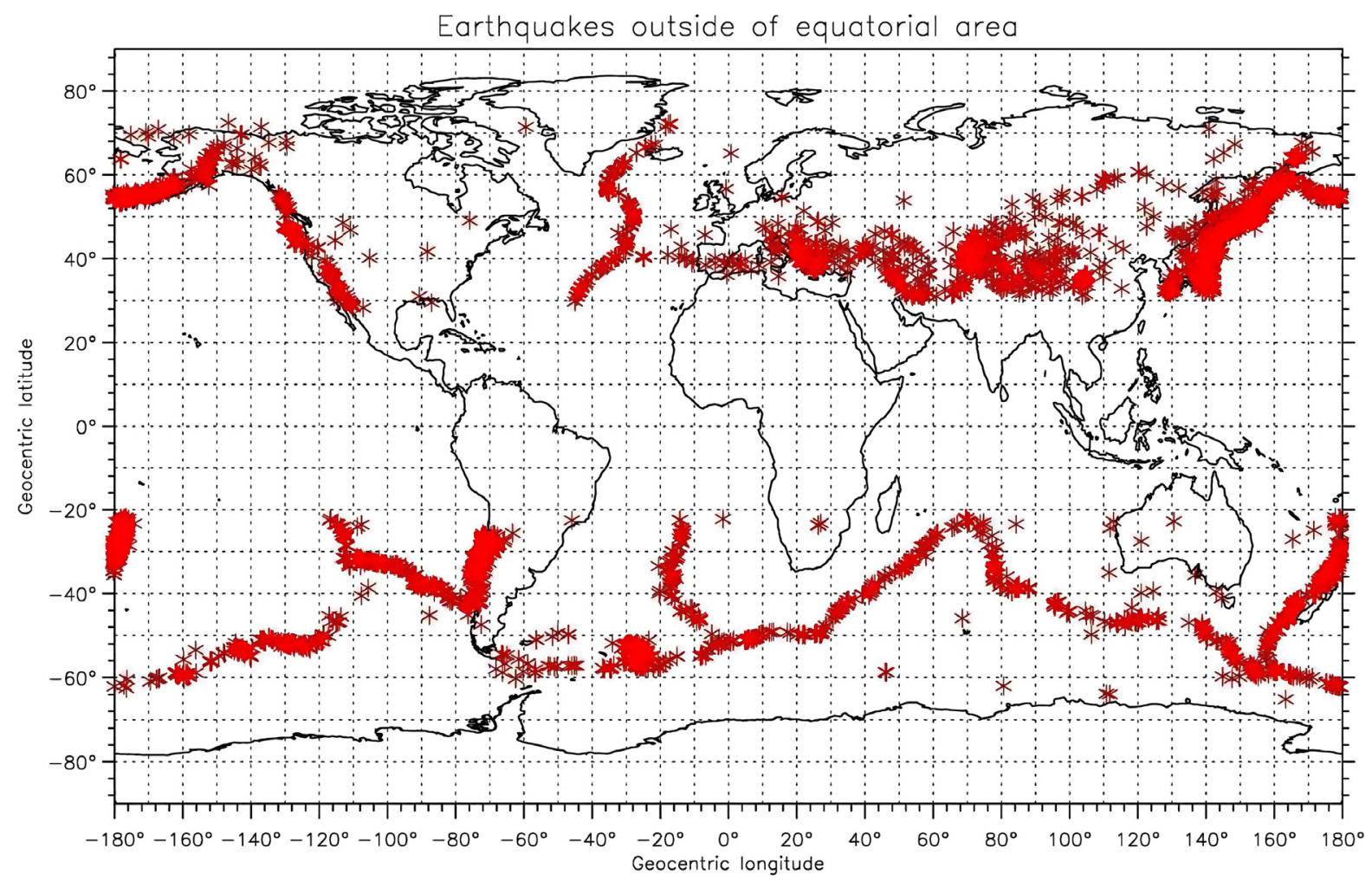

Figure 1. Using the USGS database the map shows the location of the earthquakes with $M \geq 4.8$ which are considered in the statistical analysis. Earthquakes with magnetic latitudes of the epicenters less than $20^{\circ}$ have been removed.

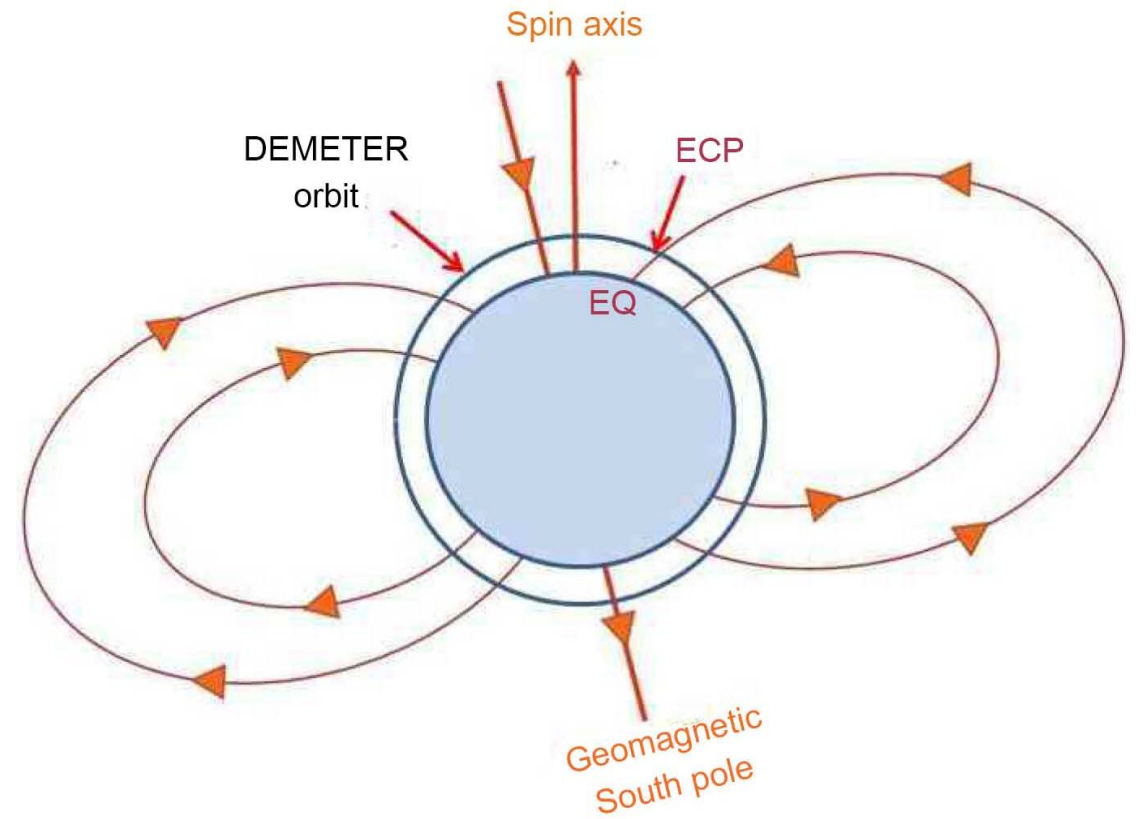

Figure 2. The Earthquake Conjugate Point (ECP) is defined as the intersection between the orbit of the satellite and the magnetic field line (red curve) of which the foot point at the Earth's surface corresponds to the earthquake epicenter.

days before earthquakes, the existence of aftershocks (which usually enter in the statistical analysis) can alter the results. The mean reason is that, at the time of 
the shocks, it is known that there are perturbations propagating in the atmosphere and then in the ionosphere. The method we use to remove the effects of the aftershocks is to not handle twice the same data. As the data is sequentially processed it means that the data related to a main shock are always considered in comparison with the data of its aftershocks. It must be noted that this method is not really efficient as thousands of earthquakes with magnitude lower than 4.8 are not considered. One must admit the hypothesis that the magnitude of the earthquakes is proportional to the amplitude of the effects we are looking for. Then, earthquakes with smaller magnitudes must have a small influence and can be removed from the statistics. This will be demonstrated later on.

\section{The Data Processing}

The whistler activity observed onboard DEMETER depends on the location, the time, the season, and also the solar cycle [20]. Then it is necessary to normalize the whistler occurrence for each earthquake in order to have a homogeneous data set. In a first step, each earthquake has been considered separately and all orbits close to the ECP have been searched during a time interval of 70 days around the earthquake time in order to determine a background value of the whistler occurrence. The distance between the orbits and the ECP has been limited to $1000 \mathrm{~km}$, and 5 concentric rings with a $200 \mathrm{~km}$ step around the ECP $(0$ - $200 \mathrm{~km}, 200-400 \mathrm{~km}, 400-600 \mathrm{~km}, 600-800 \mathrm{~km}, 800-1000 \mathrm{~km}$ ) have been considered to gradually check the whistler occurrence when the satellite moves away from the ECP (Figure 3). This largest distance of $1000 \mathrm{~km}$ is in relation with the estimation of the size of earthquake preparation zones [21].

The data processing used to drive the background whistler rate for a given earthquake is described hereafter. Considering all orbits passing less than 1000 $\mathrm{km}$ away from the ECP from 35 days before and up to 35 days after the earthquake occurring time, we can build a $70 \times 5$ matrix filled by the recorded whistler rates for the 70 days and the 5 rings. Depending on the position and time of the earthquake, all cells are not necessarily filled up but they will be used to define a background, i.e., an average whistler rate which is characteristic of the region where the EPC is, and of the season when the earthquake $i$ occurs. It means that for an earthquake $i$ all values in the $70 \times 5$ cells are averaged to calculate a background whistler rate $W^{i}$. This background whistler rate $W^{i}$ is normalized to take into account the surfaces of the rings around the ECP (Figure 3). It is easy to show that, if $S$ is the surface of the $200 \mathrm{~km}$ radius circle around the ECP, the 4 successive rings have a surface of $3 \mathrm{~S}, 5 \mathrm{~S}, 7 \mathrm{~S}$, and $9 \mathrm{~S}$. Then $W^{i}$ is calculated as

$$
W^{i}=\left(v_{1}+3 * v_{2}+5 * v_{3}+7 * v_{4}+9 * v_{5}\right) / 25 .
$$

where $v_{k}$ is the averaged whistler rate measured in the ring $k$ during the 70 days. Among the 70 days we select a time interval around the time of the earthquake $i$ between -15 days and +5 days to count the whistler rate $w_{j, k}$ in each cell $(j, k)$ where $j$ varies from 1 to 20 and $k$ from 1 to 5 (20 days and 5 distances). Then we normalized these $w_{j, k}$ of each cell $(j, k)$ by dividing by $W^{i}$ 


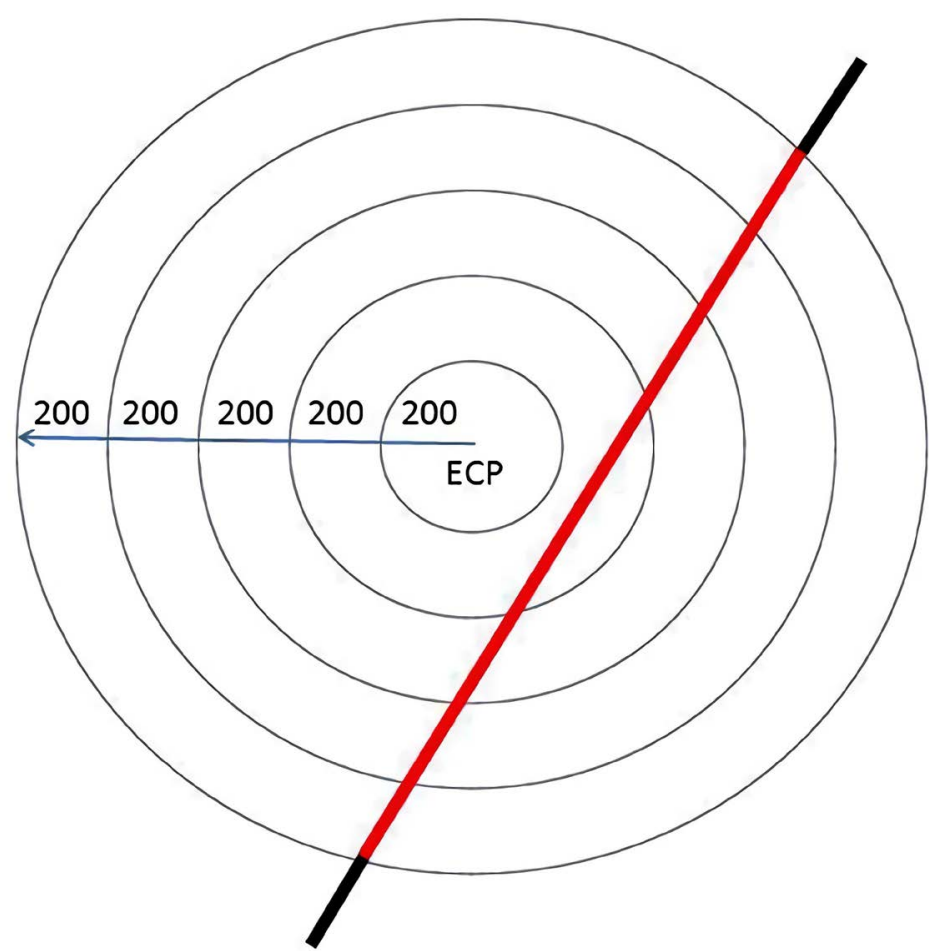

Figure 3. Pattern of rings around the ECP. Their radiuses increase by step of $200 \mathrm{~km}$. The red part of the straight line represents the projection of a satellite orbit where data are recorded. In this example they are no data recorded in the area less than $200 \mathrm{~km}$ from the ECP.

$$
R_{j k}^{i}=w_{j k} / W^{i}
$$

Therefore for each earthquake we have a grid with 100 cells. Finally, all N earthquakes are considered as we will use a superposed epoch method to represent the data. When all earthquakes have been processed we have $n_{j, k}$ normalized values in the cell $(j, k)$ and a total of $N_{V}$ normalized values in the grid.

$$
N_{V}=\sum_{j=1}^{20} \sum_{k=1}^{5} n_{j k}
$$

In a second step we calculate the average quantity $\mu$ of these $N_{V}$ normalized values and the corresponding variance $\sigma$ in order to obtain standardized values in the entire grid.

$$
S_{j k}^{i}=\left[R_{j k}^{i}-\mu\right] / \sigma \text { with } \mu=\sum_{i j k} R_{j k}^{i} / N_{V} \text { and } \sigma=\sqrt{\sum_{i j k}\left(R_{j k}^{i}-\mu\right)^{2} / N_{V}}
$$

In each cell of the grid of the superposed epoch method we plot the average of these standardized values:

$$
\overline{S_{j k}}=\frac{1}{n_{j k}} \sum_{i=1}^{n_{j k}} S_{j k}^{i}
$$

where $n_{j k}$ is always less than $N$. The results are shown in Figure 4 and Figure 5 top for $M \geq 4.8$ and $\mathrm{d} \leq 20 \mathrm{~km}$, and in Figure 5 bottom for $M \geq 5.4$. They are discussed in the next section. 


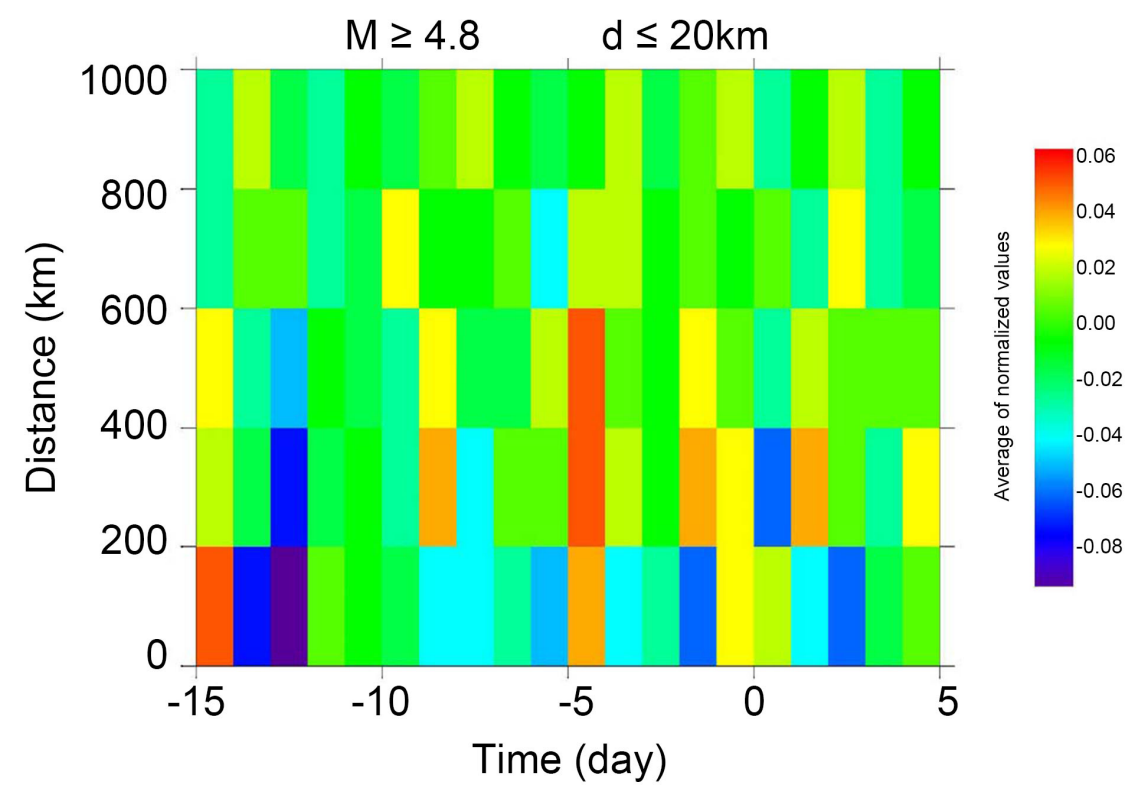

Figure 4. Representation of the superposed epoch method as function of the days around the earthquake time (all earthquakes occur at the time 0 ) and as function of the distance from the ECP. It concerns earthquakes with $\mathrm{M} \geq 4.8$ and $\mathrm{d} \leq 20 \mathrm{~km}$. On the right, the color scale gives the average of the standardized values.

\section{Discussions}

The property of the standardized values $S_{j k}^{i}$ given by Equation (4) is that their mathematical expectation is zero, i.e.

$$
E\left[S_{j k}^{i}\right]=0
$$

Another property of the mathematical expectation is that if $X$ and $Y$ are two random variables, then the mathematical expectation of the sum of these two variables is equal to the sum of the mathematical expectation of $X$ and the mathematical expectation of $Y$, i.e., $E[\mathrm{X}+\mathrm{Y}]=E[X]+E[Y]$. Then we can write:

$$
E\left[S^{i}\right]=\sum_{j k} E\left[S_{j k}^{i}\right]=0
$$

It means that if we consider that the fluctuations of the standardized values must be identical in all cells of the grid the averaged values in all cells must be zero or very close to zero. This is the case in Figure 4. Looking to the amplitudes of the color scales of Figure 4 and Figure 5 top one can see that the values in the grid are very small and oscillating around zero. Obviously this is not the case in Figure 5 bottom where one averaged value departs from zero and is particularly higher in the cell ([0, - 1 day], [0 - $200 \mathrm{~km}])$. This underlines the unusual behavior of the data in this cell.

Figure 6 shows the result of a further analysis which has been done to check the influence of the magnitude $M$ and the depth $d$ of the earthquakes. It represents the average of the standardized values in the cell ([0, - 1 day], [0 - 200 $\mathrm{km}]$ ) as function of $\mathrm{M}$ and for a depth less than $20 \mathrm{~km}$ and less than $50 \mathrm{~km}$. One can see that the effect (high whistler rate) is only significant when the magnitude 

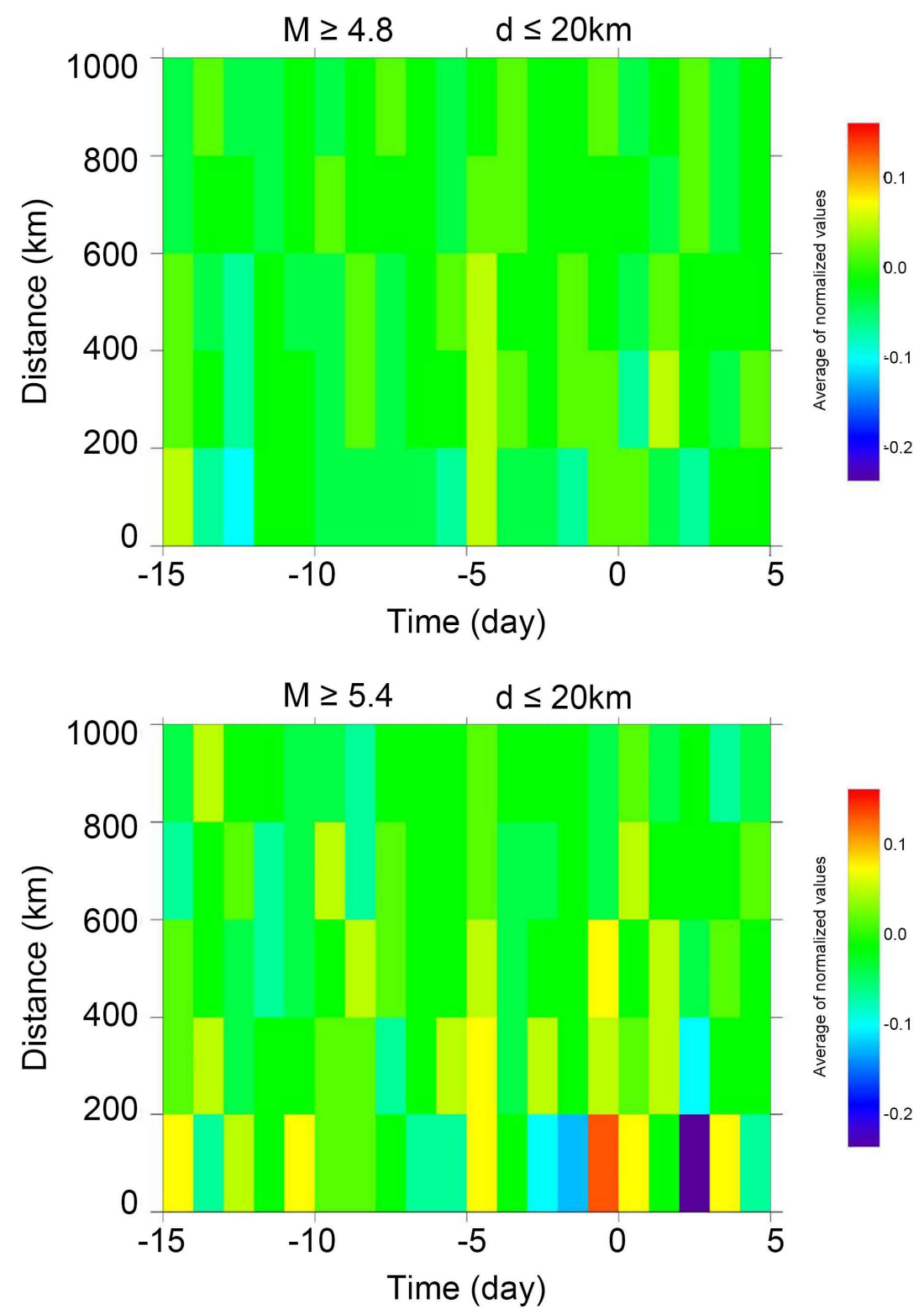

Figure 5. In order to underline the variation as function of the magnitude, the top panel is identical to Figure 4 but with the same color scale as the bottom panel which is for earthquakes with $\mathrm{M} \geq 5.4$ and $\mathrm{d} \leq 20 \mathrm{~km}$.

is larger than 5.2. The effect is lower when the depth of the earthquakes increases as it is in the analysis shown in [14].

It is possible to quantify the effect of seismic activity on the whistler occurrence. Figure 7 is very similar to Figure 6 but it represents the percentage of whistler rate increase relatively to the background, i.e. the following quantity

$$
\text { 100. } *\left[\frac{1}{n_{j k}} \sum_{i=1}^{n_{j k}} R_{j \mathrm{k}}^{i}-\mu\right] / \mu
$$

where $R_{j k}^{i}$ is given by Equation (2) and the indexes $j$ and $k$ corresponds to the cell $[0,-1$ day] and $[0-200 \mathrm{~km}]$ respectively. 


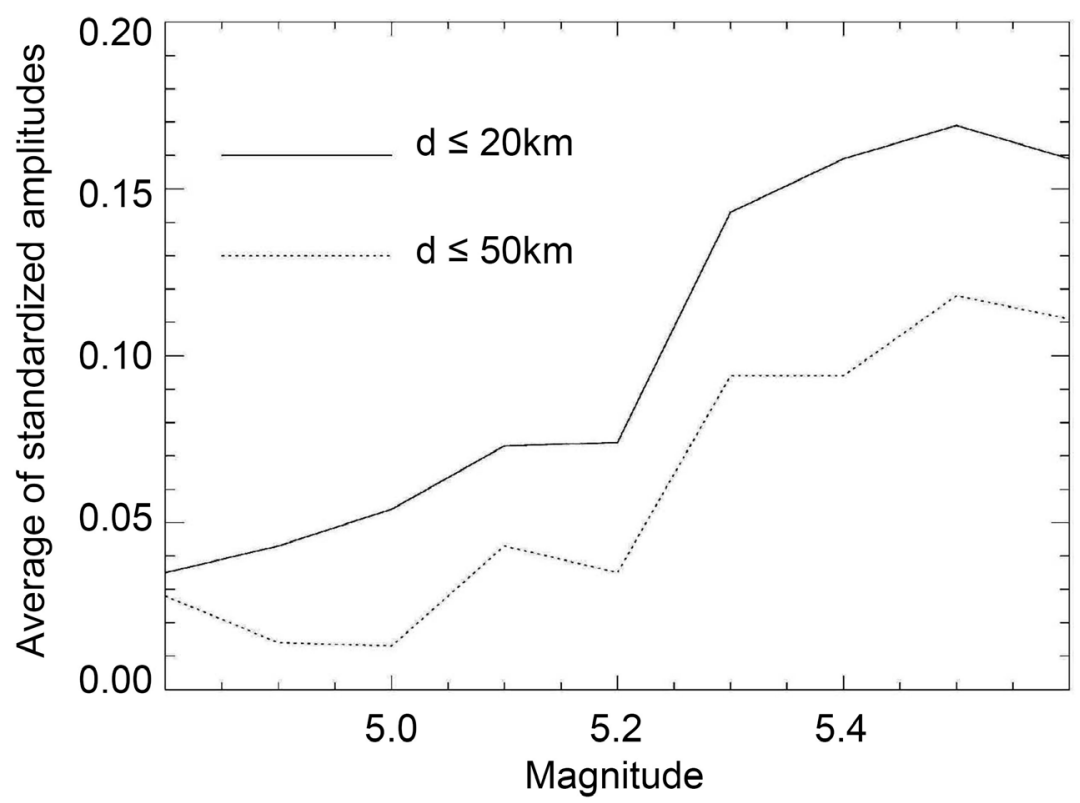

Figure 6. Variation of the amplitude in the cell [0,- 1 day], [0 - $200 \mathrm{~km}]$ as function of the earthquake magnitude for a depth $\leq 20 \mathrm{~km}$ and a depth $\leq 50 \mathrm{~km}$.

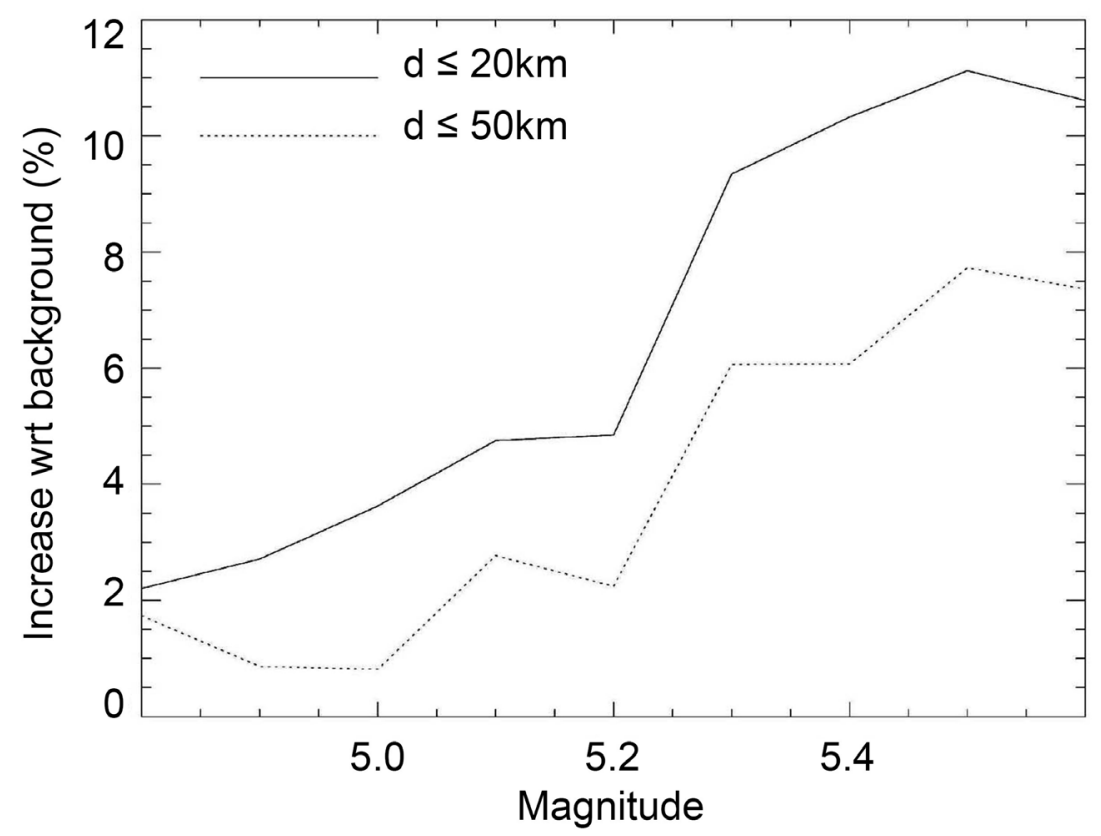

Figure 7. Percentage of whistler rate increase as function of the earthquake magnitude for a depth $\leq 20 \mathrm{~km}$ and a depth $\leq 50 \mathrm{~km}$.

One can see that the whistler rate increases by $11 \%$ at less than $200 \mathrm{~km}$ from the ECP and one day before earthquakes with $M \geq 5.5$ and $d \leq 20 \mathrm{~km}$. It is difficult to check if this percentage again increases for earthquakes with larger magnitudes because their number dramatically decreases and the statistic would not be meaningful anymore. It is also shown in Figure 7 that the percentage decreases for deeper earthquakes as expected. 
The same data processing has been done for "random" earthquakes, i.e. the time of each earthquake has been shifted forwards 25 days. The result is shown in Figure 8 for "random" earthquakes with $M \geq 5.4$ and $\mathrm{d} \leq 20 \mathrm{~km}$ and it can be compared with Figure 5 bottom. One can see that there is no link with the time of the "random" earthquakes. The reason is that, with our shift of the time of earthquakes, we have suppressed the time relation between whistler observations onboard DEMETER and large magnitude earthquakes.

Why such small increase of whistler observations onboard DEMETER can occur prior to earthquakes? This is due to important variation of parameters in the atmosphere and the corresponding consequences on the ionospheric absorption of the energy of sferics. Many papers related to atmospheric observations at the time of earthquakes have been published. Change of meteorological parameters and particularly increase of temperature has been noticed by [22] before strong earthquakes in Kamchatka. It has been mentioned that the perturbations of the electric conductivity of the atmosphere caused by the ionized gas release may induce lightning discharges [23]. Possible effects of radon and aerosol injection in the atmosphere prior to earthquakes have been mentioned by [24]. Anomalous cloud formation one week before a M7.8 earthquake in Iran has been reported in [25]. Thermal atmospheric irregularities have been observed in [26] prior to a M7.8 earthquake in Mexico.

Modelling has been also done. A model was discussed by [27] to explain how thunderclouds can be produced in the atmosphere above the sea before earthquakes. It involves atmospheric gradient of temperature and electrical charges induced by gas release on the sea surface. The model described in [26] is related to atmospheric changes due to air ionization by radon, water molecules attachment

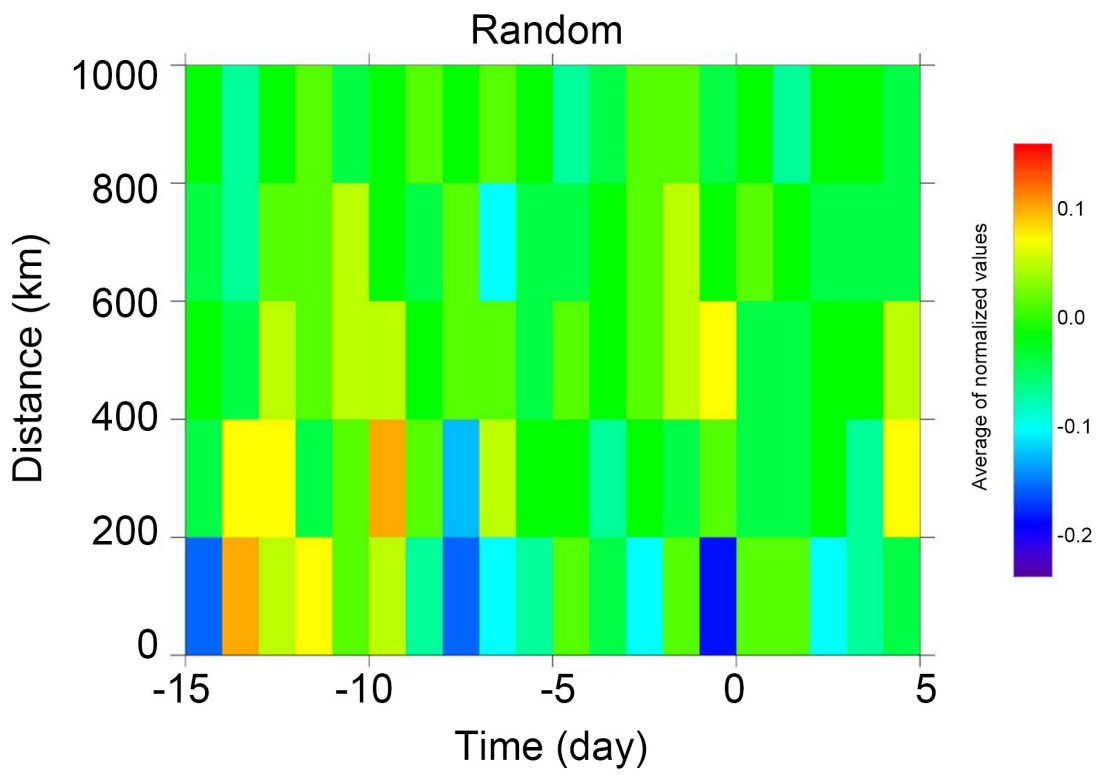

Figure 8. Similar to Figure 5 (including the color scale) but when the time of the earthquakes with $\mathrm{M} \geq 5.4$ and $\mathrm{d} \leq 20 \mathrm{~km}$ is shifted forwards 25 days. Data processing is identical as before. 
to these ions, and at the end, a heat increase. More generally, these phenomena are associated to the so-called Lithosphere-Atmosphere-Ionosphere Coupling (LAIC) described for example in [28] [29] [30] [31] [32], and to the change in the global electric circuit which exists between the Earth's surface and the bottom of the ionosphere at the time of earthquakes [33] [34].

\section{Conclusions}

The occurrence of low dispersion whistlers observed by the satellite DEMETER has been correlated with the seismic activity. The number of low dispersion whistlers is linked to the number of lightning strokes occurring below the satellite except in the vicinity of the magnetic equator. Then the study is related to earthquakes located outside this area. Earthquakes with $M \geq 4.8$ and various depths have been considered. Our analysis includes a comparison with the background thunderstorm activity and a superposed epoch method to consider all earthquakes. The main result is that an $11 \%$ increase of whistlers is observed the day before earthquakes with $\mathrm{M} \geq 5.5$ and $\mathrm{d} \leq 20 \mathrm{~km}$ at a distance less than $200 \mathrm{~km}$ from the epicenters. No significant relation is observed for earthquakes with $\mathrm{M} \leq 5.2$.

The major question is: Could this result be useful for earthquake prediction? Unfortunately not because the lightning strokes which produce whistlers are the most common events occurring in the Earth's atmosphere (about 2000 thunderstorms are active at any time [35]). This study is just a new proof that there is a LAIC mechanism prior to large and shallow earthquakes.

The DEMETER satellite is over an earthquake epicenter only a few minutes per day and only at a given local time. To remove this constraint, it is possible in the future to use the data of the World Wide Lightning Location Network [36] in order to perform a similar analysis.

\section{Acknowledgements}

This study is related to data recorded by the RNF experiment of the microsatellite DEMETER which was operated thanks to the French Centre National d'Etudes Spatiales (CNES). The DEMETER data shown in the paper can be downloaded from https://cdpp-archive.cnes.fr/.

\section{Conflicts of Interest}

The authors declare no conflicts of interest regarding the publication of this paper.

\section{References}

[1] Terada, T. (1931) Relation between Frequencies of Earthquake and Thunderstorm. Proceedings of the Imperial Academy, 7, 341-343. https://doi.org/10.2183/pjab1912.7.341

[2] De, S.S., De, B.K., Bandyopadhyay, B., Paul, S., Haldar, D.K., Bhowmick, A., Barui, 
S. and Ali, R. (2010) Effects on Atmospherics at $6 \mathrm{kHz}$ and $9 \mathrm{kHz}$ Recorded at Tripura during the India-Pakistan Border Earthquake. Natural Hazards and Earth System Sciences, 10, 843-855. https://doi.org/10.5194/nhess-10-843-2010

[3] Mullayarov, V.A., Druzhin, G.I., Argunov, V.V., Abzaletdinova, L.M. and Mel'nikov, A.N. (2014) Variations of VLF Radio Signals and Atmospherics during the Deep Earthquake with $M=8.2$ Occurred on 24 May 2013 near Kamchatka Peninsula. Natural Science, 6, 144-149. https://doi.org/10.4236/ns.2014.63019

[4] Mikhailov, Yu.M., Mikhailova, G.A., Kapustina, O.V., Druzhin, G.I. and Smirnov, S.E. (2006) Electric and Electromagnetic Processes in the near Earth Atmosphere before Earthquakes at Kamchatka. Geomagnetism and Aeronomy, 46, 796-808. https://doi.org/10.1134/S0016793206060156

[5] Kabanov, V.V. and Sharafutdinov, V.M. (2013) Variations in the Power Spectrum Density of Whistlers in the Frequency Band 8-40 kHz during Earthquake Preparation. Geomagnetism and Aeronomy, 53, 534-540. https://doi.org/10.1134/S0016793213030080

[6] Freund, F.T. (2003) Rocks That Crackle and Sparkle and Glow: Strange Pre-Earthquake Phenomena. Journal of Seismic Exploration, 17, 37-71.

[7] Gousheva, M.N., Glavcheva, R.P., Danov, D.L., Hristov, P.L., Kirov, B.B. and Georgieva, K.Y. (2008) Electric Field and Ion Density Anomalies in the Mid Latitude Ionosphere: Possible Connection with Earthquakes? Advances in Space Research, 42, 206-212. https://doi.org/10.1016/j.asr.2008.01.015

[8] Yamada, T. and Oike, K. (1999) On the Increase of Electromagnetic Noises before and after the 1995 Hyogo Ken Nanbu Earthquake. In: Hayakawa, M., Ed., Atmospheric and Ionospheric Electromagnetic Phenomena Associated with Earthquakes, TERRAPUB, Tokyo, 417-427.

[9] Ondoh, T. (2009) Investigation of Precursory Phenomena in the Ionosphere, Atmosphere and Groundwater before Large Earthquakes of $\mathrm{M}>6.5$. Advances in Space Research, 43, 214-223. https://doi.org/10.1016/j.asr.2008.04.003

[10] Mullayarov, V.A., Argunov, V.V., Abzaletdinova, L.M. and Kozlov, V.I. (2012) Ionospheric Effects of Earthquakes in Japan in March 2011 Obtained from Observations of Lightning Electromagnetic Radio Signals. Natural Hazards and Earth System Sciences, 12, 3181-3190. https://doi.org/10.5194/nhess-12-3181-2012

[11] Daneshvar, M.R.M. and Freund, F.T. (2017) Remote Sensing of Atmospheric and Ionospheric Signals prior to the Mw 8.3 Illapel Earthquake, Chile 2015. In: The Chile-2015 (Illapel) Earthquake and Tsunami, Birkhäuser, Cham, 157-191. https://doi.org/10.1007/978-3-319-57822-4_13

[12] Asada, T., Baba, H., Kawazoe, M. and Sugiura, M. (2001) An Attempt to Delineate Very Low Frequency Electromagnetic Signals Associated with Earthquakes. Earth, Planets and Space, 53, 55-62. https://doi.org/10.1186/BF03352362

[13] Liu, J.Y., Wang, K., Chen, C.H., Yang, W.H., Yen, Y.H., Chen, Y.I., Hatorri, K., Su, H.T., Hsu, R.R. and Chang, C.H. (2013) A Statistical Study on ELF-Whistlers/Emissions and $\mathrm{M} \geq 5.0$ Earthquakes in Taiwan. Journal of Geophysical Research: Space Physics, 118, 3760-3768. https://doi.org/10.1002/jgra.50356

[14] Liu, J.Y., Chen, Y.I., Huang, C.H., Ho, Y.Y. and Chen, C.H. (2015) A Statistical Study of Lightning Activities and $M \geq 5.0$ Earthquakes in Taiwan during 1993-2004. Surveys in Geophysics, 36, 851-859. https://doi.org/10.1007/s10712-015-9342-2

[15] Derr, J.S. (1973) Earthquake Lights: A Review of Observations and Present Theories. Bulletin of the Seismological Society of America, 63, 2177-2187.

[16] Enomoto, Y. and Zheng, Z. (1998) Possible Evidences of Earthquake Lightning Ac- 
companying the 1995 Kobe Earthquake Inferred from the Nojima Fault Gouge. $f$ Geophysical Research Letters, 25, 2721-2724. https://doi.org/10.1029/98GL02015

[17] Jánský, J. and Pasko, V.P. (2018) Earthquake Lights: Mechanism of Electrical Coupling of Earth's Crust to the Lower Atmosphere. Journal of Geophysical Research: Atmospheres, 123, 8901-8914. https://doi.org/10.1029/2018JD028489

[18] Elie, F., Hayakawa, M., Parrot, M., Pinçon, J.-L. and Lefeuvre, F. (1999) Neural Network System for the Analysis of Transient Phenomena on Board the DEMETER Micro-Satellite. IEICE Transactions on Fundamentals of Electronics, Communications and Computer Sciences, 82, 1575-1581.

[19] Buzzi, A. (2007) DEMETER Satellite Data Analysis of Seismo-Electromagnetic Signals. PhD Thesis, Univ. Rome, Roma.

[20] Parrot, M., Pinçon, J.-L. and Shklyar, D. (2019) Short-Fractional Hop Whistler Rate Observed by the Low-Altitude Satellite DEMETER at the End of the Solar Cycle 23. Journal of Geophysical Research: Space Physics, 124, 3522-3531. https://doi.org/10.1029/2018JA026176

[21] Dobrovolsky, I.P., Zubkov, S.I. and Miachkin, V.I. (1979) Estimation of the Size of Earthquake Preparation zones. Pure and Applied Geophysics, 117, 1025-1044. https://doi.org/10.1007/BF00876083

[22] Smirnov, S.E., Mikhailova, G.A., Mikhailov, Y.M. and Kapustina, O.V. (2017) Effects of Strong Earthquakes in Variations of Electrical and Meteorological Parameters of the Near-Surface Atmosphere in Kamchatka Region. Geomagnetism and Aeronomy, 57, 610-617. https://doi.org/10.1134/S0016793217050164

[23] Schekotov, A., Zhou, H.J., Qiao, X. and Hayakawa, M. (2016) ULF/ELF Atmospheric Radiation in Possible Association to the 2011 Tohoku Earthquake as Observed in China. Earth Science Research, 5, 47-58. https://doi.org/10.5539/esr.v5n2p47

[24] Liperovsky, V.A., Meister, C.V., Liperovskaya, E.V., Davidov, V.F. and Bogdanov, V.V. (2005) On the Possible Influence of Radon and Aerosol Injection on the Atmosphere and Ionosphere before Earthquakes. Natural Hazards and Earth System Science, 5, 783-789. https://doi.org/10.5194/nhess-5-783-2005

[25] Daneshvar, M., Tavousi, T. and Khosravi, M. (2014) Synoptic Detection of the Short-Term Atmospheric Precursors Prior to a Major Earthquake in the Middle East, North Saravan M 7.8 Earthquake, SE Iran. Air Quality and Atmosphere Health, 7, 29-39. https://doi.org/10.1007/s11869-013-0214-y

[26] Pulinets, S.A., Ouzounov, D., Ciraolo, L., Singh, R., Cervone, G., Leyva, A., Dunajecka, M., Karelin, A.V., Boyarchuk, K.A. and Kotsarenko, A. (2006) Thermal, Atmospheric and Ionospheric Anomalies around the Time of the Colima M 7.8 Earthquake of 21 January 2003. Annales Geophysicae, 24, 835-849. https://doi.org/10.5194/angeo-24-835-2006

[27] Ruzhin, Y. and Nomicos, C. (2007) Radio VHF Precursors of Earthquakes. Natural Hazards, 40, 573-583. https://doi.org/10.1007/s11069-006-9021-1

[28] Pulinets, S.A., Morozova, L.I. and Yudin, I.A. (2014) Synchronization of Atmospheric Indicators at the Last Stage of Earthquake Preparation Cycle. Research in Geophysics, 4, 45-50. https://doi.org/10.4081/rg.2014.4898

[29] Hayakawa, M. (1999) Atmospheric and Ionospheric Electromagnetic Phenomena Associated with Earthquakes. Terra Scientific Publishing Company, Tokyo.

[30] Hayakawa, M. and Molchanov, O.A. (2002) Seismo Electromagnetics: Lithosphere-Atmosphere-Ionosphere Coupling. Terra Scientific Publishing Company, 
Tokyo.

[31] Kuo, C.L., Lee, L.C. and Huba, J.D. (2014) An Improved Coupling Model for the Lithosphere-Atmosphere-Ionosphere system. Journal of Geophysical Research, 119, 3189-3205. https://doi.org/10.1002/2013JA019392

[32] Pulinets, S. and Davidenko, D. (2014) Ionospheric Precursors of Earthquakes and Global Electric Circuit. Advances in Space Research, 53, 709-723. https://doi.org/10.1016/j.asr.2013.12.035

[33] Harrison, R.G., Aplin, K.L. and Rycroft, M.J. (2010) Atmospheric Electricity Coupling between Earthquake Regions and the Ionosphere. Journal of Atmospheric and Solar-Terrestrial Physics, 72, 376-381. https://doi.org/10.1016/j.jastp.2009.12.004

[34] Harrison, R.G., Aplin, K.L. and Rycroft, M.J. (2014) Brief Communication: Earthquake-Cloud Coupling through the Global Atmospheric Electric Circuit. Natural Hazards and Earth System Sciences, 14, 773-777. https://doi.org/10.5194/nhess-14-773-2014

[35] Uman, M.A. (1986) All about Lightning. Dover Publications, New York.

[36] Lay, E.H., Jacobson, A.R., Holzworth, R.H., Rodger, C.J. and Dowden, R.L. (2007) Local Time Variation in Land/Ocean Lightning Flash Density as Measured by the World Wide Lightning Location Network. Journal of Geophysical Research: Atmospheres, 112, D13111. https://doi.org/10.1029/2006JD007944 